\title{
A emancipação dos estudos da deficiência
}

The Emancipation of Disability Studies

L'émancipation des études du handicap

Bruno Sena Martins, Fernando Fontes, Pedro Hespanha e Aleksandra

Berg

\section{(2) OpenEdition}

\section{Journals}

Edição electrónica

URL: http://journals.openedition.org/rccs/5014

DOI: $10.4000 /$ rccs. 5014

ISSN: 2182-7435

\section{Editora}

Centro de Estudos Sociais da Universidade de Coimbra

Edição impressa

Data de publição: 1 Setembro 2012

Paginação: 45-64

ISSN: 0254-1106

\section{Refêrencia eletrónica}

Bruno Sena Martins, Fernando Fontes, Pedro Hespanha e Aleksandra Berg, « A emancipação dos estudos da deficiência », Revista Crítica de Ciências Sociais [Online], 98 | 2012, colocado online no dia 06 junho 2013, criado a 30 abril 2019. URL : http://journals.openedition.org/rccs/5014 ; DOI :

$10.4000 /$ rccs. 5014 


\title{
BRUNO SENA MARTINS, FERNANDO FONTES, PEDRO HESPANHA, ALEKSANDRA BERG
}

\section{A emancipação dos estudos da deficiência*}

\begin{abstract}
Não obstante o interesse das ciências sociais nas questões de exclusão e desigualdade, a questão da deficiência, enquanto eixo central de reflexão, permanece ausente em muitos contextos académicos. A emergência dos Disability Studies deve muito aos contextos em que o ativismo das pessoas com deficiência fez relevar as condições estruturais que oprimem e negligenciam as experiências da deficiência. Nesse sentido, tendo em conta as especificidades do ambiente sociopolítico português, no presente texto desenvolvem-se duas linhas de inquirição. Primeira, quais os desafios para que na academia portuguesa vingue a perspetiva de fazer da deficiência uma questão central, em termos passíveis de confrontar o silenciamento que as vozes e experiências das pessoas com deficiência enfrentam na vida social? Segunda, que importância deve ser dada ao engajamento da investigação com um paradigma ético e político em prol dos direitos das pessoas com deficiência?
\end{abstract}

Palavras-chave: deficiência; discriminação; emancipação; estudos da deficiência; investigação emancipatória.

\section{Introdução}

As pessoas com deficiência constituem um dos grupos social e economicamente mais excluídos, como a sua sobrerrepresentação entre as camadas mais pobres da população permite perceber (Beresford, 1996; Coleridge, 1993; Turmusani, 2002). Para esta realidade, muito tem contribuído a invisibilidade social das pessoas com deficiência, numa lógica em que invisibilidade e exclusão recursivamente se perpetuam. Esta omissão é largamente reproduzida pelas ciências sociais, cujo investimento analítico pouco tem considerado a deficiência enquanto uma das linhas mais decisivas na produção e perpetuação de desigualdades nas sociedades modernas ocidentais

\footnotetext{
* Este artigo foi produzido no âmbito do projeto "Da lesão vertebro-medular à inclusão social: a deficiência enquanto desafio pessoal e sociopolítico", financiado pela Fundação para a Ciência e a Tecnologia (PTDC/CS-SOC/102426/2008).
} 
(Finkelstein, 1999; Barnes, 1997; Davis, 2002). Este "corpo silencioso" de que Robert Murphy (1990) fala, para dar conta do fenómeno de invisibilidade estrutural das pessoas com deficiência, é particularmente contundente na descrição da realidade social portuguesa. Em países como os Estados Unidos da América e o Reino Unido este retrato foi alterado, ao longo das últimas décadas, com a emergência no início dos anos 1970 de movimentos sociais de pessoas com deficiência e com a consequente politização da questão da deficiência (Oliver, 1996; Barnes e Mercer, 2002; Hanh, 2002; Thomas, 2002). Nestes contextos, a politização da deficiência foi acompanhada pela emergência na academia dos estudos da deficiência (Disability Studies), uma área de investigação matricialmente assente num compromisso político com a denúncia da opressão social das pessoas e na aspiração de uma sociedade mais inclusiva.

No presente artigo procura-se pulsar as possibilidades e desafios para a constituição em Portugal de um paradigma de investigação emancipatória na deficiência. Na primeira parte apresenta-se uma breve revisão dos diferentes modelos utilizados para conceptualizar a deficiência, bem como dos principais paradigmas de investigação que lhes são correlatos. Na segunda parte defendemos a centralidade e relevância de um paradigma de investigação emancipatória nas leituras académicas da realidade da deficiência. Explanam-se ainda alguns dos princípios que deverão definir as práticas da investigação emancipatória na área da deficiência. $\mathrm{Na}$ terceira e última parte refletimos sobre os desafios, teóricos e metodológicos, que as especificidades da sociedade portuguesa colocam à realização de uma investigação emancipatória nesta área.

\section{Deficiência: modelos e abordagens}

A análise da deficiência enquanto questão social é um fenómeno recente. $\mathrm{Na}$ verdade, constituída pela biomedicina moderna ocidental como uma forma particular de patologia (Striker, 1999; Martins, 2006), a deficiência tem sido reduzida às "inconformidades" do corpo individual e a uma conceção fatalista de "tragédia pessoal" (Oliver, 1990). Desse modo, os constrangimentos e barreiras que as pessoas com deficiência enfrentam no seu dia a dia tendem a ser naturalizados enquanto produto das suas putativas limitações funcionais. Estamos perante uma das lógicas de produção de não existência da razão moderna, nos termos em que Boaventura Sousa Santos (2002) a define, particularmente a lógica da classificação social. Esta funda-se numa "monocultura da naturalização das diferenças" cujo mecanismo central é a "distribuição das populações por categorias que naturalizam as diferenças" (ibidem: 247). A exclusão e silenciamento perpetrados por esta 
via imbricam-se decisivamente com a vocação da epistemologia moderna para o reducionismo biológico (Good, 1994).

O modelo médico ou individual de deficiência, indisputado até à emergência dos movimentos sociais de pessoas com deficiência (Campbell e Oliver, 1996), ratificou uma construção das pessoas com deficiência enquanto sujeitos passivos, dependentes de cuidados. $\mathrm{O}$ facto de a deficiência ter sido definida como objeto médico, respeitante ao corpo individual, foi um fator decisivo para que se tivessem privilegiado respostas resolutamente centradas no indivíduo no seio de uma "abordagem reabilitacional" (Striker, 1999). As respostas informadas por esta abordagem sempre se basearam na ideia de que as decisões sobre a vida das pessoas com deficiência deveriam estar a cargo dos profissionais, as vanguardas do saber. Tal relação de autoridade fundou uma desqualificação das perspetivas das pessoas com deficiência, perspetivas em que os limites e desigualdades impostos pela ordem social tendem a ocupar um lugar central.

A crescente contestação ao modelo médico de deficiência levou a Organização Mundial de Saúde (OMS) a publicar, em 1980, a International Classification of Functioning, Impairments Disabilities and Handicaps (ICIDH) (OMS, 1980). No entanto, a perspetiva adotada por esta classificação, que nas suas definições centrais (deficiências, incapacidades e desvantagens) consagrou de forma tangencial os "fatores sociais e culturais", mostrou-se incapaz de abandonar uma perspetiva mormente individualista da deficiência (Barnes e Mercer, 2003; Barnes, Mercer e Shakespeare, 2000), ancorada numa "hegemonia da normalidade" (Davis, 1995).

Denunciando os limites do modelo individual ou médico para reconhecer o contexto sociopolítico da deficiência, desenvolveu-se no contexto britânico uma proposta que se lhe opôs, e que ficaria conhecida por modelo social da deficiência. O modelo social de deficiência vem propor uma reconceptualização da deficiência (disability) como uma forma de opressão social (UPIAS, 1976), encetando, assim, uma nova perspetiva paradigmática que se mostrou fortemente mobilizadora da insurgência política das pessoas com deficiência. A assunção de que os problemas implicados pela deficiência se prendem com as estruturas sociais e não com as funcionalidades do corpo teve igualmente importantes implicações em termos de capacitação identitária, na medida em permitiu às pessoas com deficiência uma renovada leitura da sua posição social contra os valores que as desqualificavam enquanto menos pessoas, irremediavelmente apartadas das atividades centrais da vida social (Gibbs, 2004). De facto, como afirma Bell Hooks noutro contexto, devemos perceber a "autoestima como uma radical agenda política" (Hooks, 1995: 119). 
Mais recentemente, o avolumar de críticas ao reducionismo médico do ICIDH e a necessidade emergente de compaginar o modelo médico e o modelo social levou à emergência de um novo modelo da deficiência, apelidado de biopsicossocial. Este modelo substancia-se na nova Classificação Internacional de Funcionalidade, Incapacidade e Saúde (ICIDH-2 ou CIF) publicada pela OMS (2001), onde a OMS reconhece a deficiência como resultado da interação entre funções do corpo, estruturas do corpo, atividades e participação, e fatores ambientais. Não obstante as alterações introduzidas, a CIF continua a ser fortemente criticada pelos defensores do modelo social. Entre as diferentes críticas é de assinalar a acusação de que a CIF continua a centrar-se nas consequências das condições médicas, perspetivando os aspetos sociais da deficiência apenas por referência aos fatores ambientais da deficiência (Barnes, Mercer e Shakespeare, 2000; Pfeiffer, 2000).

Longe de ser irrelevante, a forma como perspetivamos a deficiência é essencial na forma como definimos os problemas e delineamos as soluções. Se isto é primordial na área das políticas sociais (Oliver e Sapey, 1999; Hespanha, 2008; Fontes, 2009), também o é na área da investigação científica, em que as diferentes conceções significam diferentes posicionamentos ante o reconhecimento e valorização da voz das pessoas com deficiência. Um bom exemplo desta relação deu-se na disputa que opôs os habitantes de um lar residencial - Le Court Cheshire Home - em Inglaterra nos anos 1960 e os investigadores do Tavistock Institut. A demanda dos residentes daquele lar residencial por um maior controlo sobre as suas vidas levou-os a convidar o Tavistock Institut para conduzir uma investigação sobre as condições de vida dos utentes do centro, na esperança de que os resultados apoiassem as suas reivindicações ante a administração do lar (Barnes, Mercer e Shakespeare, 2000; Mercer, 2002). Os investigadores concluíram que, não obstante muitas das reivindicações dos utentes do lar serem justas, eram, todavia, inexequíveis porque exigiam demasiadas transformações do statu quo; recomendaram, portanto, que se retomasse a prática profissional tradicional (ibidem). Para os residentes da instituição, as conclusões dos investigadores constituíram uma traição, tendo sido mesmo acusados de parasitismo (Hunt, 1981), na medida em que se limitaram a cuidar "apenas dos seus interesses profissionais e académicos fazendo com que os residentes se sentissem explorados, abusados e traídos" (Mercer: 2002: 229). Este episódio, marcante na história das pessoas com deficiência e na história dos estudos da deficiência, exemplifica claramente o esgotamento de um paradigma científico e o aflorar de um novo paradigma. Este incidente demonstrou a ineficácia de um paradigma científico positivista, que defende a ideia de uma ciência exata, supostamente objetiva, neutral e distanciada, 
tal como perfilhado pelos investigadores do Tavistock Institut. Demonstrou, igualmente, a necessidade de uma ciência crítica, politicamente ancorada e capaz de produzir mudança positiva na vida das pessoas com deficiência, na sociedade e na própria forma de fazer ciência. A esta nova forma de fazer investigação na área da deficiência, seguindo de perto a formulação que ganhou alargado reconhecimento no contexto britânico (cf. Mercer, 2002), poderíamos chamar "Investigação Emancipatória da Deficiência"1 (Oliver, 1992).

\section{Estudos da deficiência e emancipação social}

O termo "Investigação Emancipatória da Deficiência" foi cunhado por Michael Oliver em 1992 (cf. Oliver, 1992). Esta visão crítica da investigação na área da deficiência emerge na década de 1960. Em termos gerais, a investigação emancipatória pode ser definida como "a capacitação das pessoas com deficiência através da transformação das condições materiais e sociais de produção da investigação" (Barnes, 2003: 6). Deste ponto de vista, a investigação emancipatória, articulada com a afirmação do modelo social da deficiência, significa também um reconhecimento por parte da academia dos termos em que a produção científica tem sido cúmplice - por ação ou omissão - com quadros sociais opressores das pessoas com deficiência (Oliver, 1997; Mercer, 2002). Reconhecido que é o lugar que os corpos e as suas diferenças ocupam nos discursos legitimadores das relações de opressão, como locus de algumas das mais fundamentais formas de desigualdade e de controlo social na sociedade contemporânea (Turner, 1994: 28), é ainda mais significativo o parco investimento crítico da investigação académica em torno da deficiência. É exatamente contra a sanção das estruturas excludentes da sociedade que a investigação emancipatória se deverá erigir. Nas palavras de Colin Barnes,

a Investigação Emancipatória dedica-se à sistemática desmistificação de estruturas e dos processos que criam a deficiência, bem como do estabelecimento de um "diálogo viável" entre a comunidade científica e as pessoas com deficiência, de modo a potenciar a sua emancipação. A concretização deste objetivo implica que os investigadores aprendam a colocar os seus conhecimentos e capacidades ao serviço das pessoas com deficiência. (Barnes, 1992: 122; tradução nossa)

Trata-se, portanto, de um reposicionamento do investigador e de uma redefinição dos papéis dos diferentes intervenientes no processo de investigação

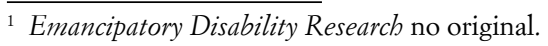


científica. Tal redefinição implica o abandono de uma visão positivista da objetividade científica e da crença na criação de um saber livre de valores, construído a partir de métodos transversais às diferentes ciências e onde o investigador assume uma posição privilegiada de poder e de neutralidade face ao processo de investigação. Pelo contrário, este novo modelo de investigação defende a necessidade de um compromisso político entre o investigador e os sujeitos investigados, capaz de questionar o postulado positivista da existência de "leis naturais" reguladoras da realidade social e revelador das relações de opressão social existentes (Barnes, 2003). Estamos perante a assunção de que a neutralidade axiológica do investigador é insustentável, o que, como Boaventura de Sousa Santos defende, não implica que se abandonem as prerrogativas de busca de objetividade:

As ciências sociais críticas têm, pois, de refundar uma das reivindicações originais da teoria critica moderna: a distinção entre objectividade e neutralidade. A objectividade decorre da aplicação rigorosa e honesta dos métodos de investigação que nos permitem fazer análises que não se reduzem à reprodução antecipada das preferências ideológicas daqueles que a levam a cabo. A objectividade decorre ainda da aplicação sistemática de métodos que permitam identificar os pressupostos, os preconceitos, os valores e os interesses que subjazem à investigação científica supostamente desprovida deles. (Santos, 1999: 207, itálico no original)

$\mathrm{Na}$ perspetiva que preconizamos, a recusa da neutralidade nos estudos da deficiência substancia-se num compromisso com a elisão das estruturas que marginalizam e silenciam as experiências das pessoas com deficiência. A objetividade traduz-se numa leitura que, sendo crítica da "hegemonia da normalidade" (Davis, 1995), assume esse mesmo lugar de enunciação; não se escusa a pensar criticamente as agendas das organizações de pessoas com deficiência; não reduz a experiência das pessoas com deficiência às dimensões passíveis de serem transformadas pelos fatores políticos e socioculturais.

Têm sido feitas várias tentativas para sintetizar os princípios essenciais da investigação emancipatória na área da deficiência (Stone e Priestley, 1996; Oliver, 1997; Mercer, 2002; Barnes, 2003). Uma leitura dos diferentes ensejos permite-nos salientar quatro princípios essenciais que devem nortear a investigação emancipatória nesta área: a adoção do modelo social enquanto ferramenta teórica e enquanto perspetiva crítica privilegiada através da qual se apreende a realidade das pessoas com deficiência; o desenvolvimento de uma ciência politicamente empenhada e comprometida com as lutas das pessoas com deficiência; a responsabilização do investigador face aos 
sujeitos da investigação - as pessoas com deficiência e as suas organizações; e, finalmente, a utilização de metodologias de investigação suficientemente adaptáveis de modo a captar a complexidade do real e a valorizar a voz das pessoas com deficiência.

\section{Metodologias}

A adoção do modelo social como estrutura conceptual para o desenvolvimento de uma investigação emancipatória significa, desde logo, questionar a medicalização e o silenciamento das experiências das pessoas com deficiência em favor de uma visibilização das estruturas de opressão social. Esta abordagem incita o investigador a centrar a sua análise na discriminação associada à deficiência (disabilism) e na sociedade onde essa discriminação e opressão têm lugar. Esta perspetiva está intimamente relacionada com a escolha de métodos e de técnicas de análise de dados. A investigação emancipatória exige uma profunda reflexão sobre a participação das pessoas com deficiência na definição e execução da pesquisa, sobre os métodos a utilizar e sobre o modo como os resultados poderão contribuir para a transformação social.

Entre os diferentes tipos de metodologias de investigação, o estudo qualitativo ganhou uma importância particular ao nível da investigação emancipatória por oferecer mais possibilidades de criação de um espaço de partilha de poder entre o investigador e o investigado, em oposição à dualidade sujeito/objeto. Entre as diferentes técnicas de recolha de dados de cariz qualitativo, as entrevistas semiestruturadas, conquanto impliquem uma discussão e validação por parte dos entrevistados, foram a técnica que mais se evidenciou. Tal fica a dever-se ao facto de esta técnica de recolha de dados restituir às pessoas com deficiência o poder sobre as suas palavras e a possibilidade de eliminar ou alterar as suas declarações iniciais. Todavia, e apesar de a investigação emancipatória ter sido associada durante muito tempo à utilização de dados e metodologias qualitativas, atualmente parece gerar-se um consenso em torno da utilização de uma multiplicidade de tipos de dados, de metodologias de investigação e de técnicas de análise de dados (Abberley, 1992; Oliver, 1997; Barnes, 2003). Assim, não obstante esta ênfase na utilização de metodologias qualitativas como única forma capaz de captar esta riqueza, Colin Barnes (2003) e Paul Abberley (1992) salientam a importância da utilização de uma multiplicidade de metodologias - qualitativas e quantitativas - como forma de captar as diferentes faces da opressão e da exclusão social a que estão sujeitas as pessoas com deficiência.

Michael Oliver (1992: 123) defende, todavia, o alcance limitado desta preocupação metodológica, afirmando que o compromisso do investigador 
é mais decisivo do que as metodologias e técnicas utilizadas. A investigação emancipatória pressupõe assim que a investigação se baseie na existência de uma interação, de base regular, entre a comunidade científica, as pessoas com deficiência e as organizações que as representam. Michael Oliver (2002) nota ainda que esta proximidade necessita de ser aprofundada através da criação de uma nova linguagem capaz de anular a distinção entre investigadores e investigados, bem como através da criação de novas ferramentas de investigação, capazes de coletivizar as experiências individuais (Oliver, 2002:4).

A alteração das relações sociais e materiais de produção científica (Oliver, 1997) constitui assim o grande desafio para os investigadores. No contexto de uma ciência crítica, estes, enquanto agentes de mudança social, terão que ter abertura para se deixarem tocar e transformar pelo processo de investigação (Oliver, 1992). Só desta forma será possível envolver o movimento de pessoas com deficiência no processo de investigação, partilhando e devolvendo-lhe o controlo sobre o mesmo. A participação transformadora das pessoas com deficiência constitui assim uma condição para a investigação emancipatória, devendo estender-se às diferentes fases do processo de investigação, desde o delineamento do projeto até à redação e apresentação das conclusões.

\section{Investigação emancipatória em Portugal}

Contrariamente à realidade de outros países, onde os Estudos da Deficiência são um campo de investigação florescente, em Portugal estes são quase inexistentes. Consequentemente, não se encontra em Portugal um corpus crítico homólogo ao das numerosas investigações que há muito denunciam a opressão e discriminação de pessoas com deficiência em países como o Reino Unido (e.g. Oliver, 1990; Barnes, 1991; Oliver e Barnes, 1998; Drake, 1999; Barton, 2001) e os Estados Unidos da América (e.g. DeJong, 1981; Hahn, 1986, 2002; Longmore e Umansky, 2001; Krieger, 2003). Além do mais, a disseminação do modelo social de deficiência e do Movimento pela Vida Independente (DeJong, 1981; Coleridge, 1993), centrais nestes países no processo de politização da questão da deficiência, é muito embrionária tanto na mobilização política de pessoas com deficiência como no meio académico nacional (Martins, 2007; Fontes, 2011a). Este alheamento epistemológico é sintomático da tenacidade com que as conceções médicas da deficiência assumem um caráter hegemónico que se vem perpetuando no contexto português, a despeito das transformações ocorridas noutras realidades sociopolíticas. Na realidade portuguesa, o estudo da deficiência tem-se restringido aos campos da psicologia, medicina e ciências da educação, campos onde 
o modelo médico tem sido dominante. Em Portugal, disciplinas como a sociologia e a antropologia, muito ligadas aos estudos da deficiência noutros países, só muito recentemente direcionaram a sua atenção para esta área de estudo. Alegamos que tal situação se deve às condições históricas, culturais, políticas e económicas de um país do sul da Europa e que as mesmas colocam desafios singulares ao desenvolvimento da Investigação Emancipatória da Deficiência em Portugal.

A ditadura que entre 1928 e 1974 se estabeleceu em Portugal teve um grande impacto em todas as esferas da sociedade portuguesa, incluindo nas vidas de pessoas com deficiência. O controlo sobre a sociedade civil impediu qualquer atividade política e o desenvolvimento de movimentos sociais até 1974. Apesar da existência de organizações de pessoas com deficiência desde os anos 1920 e 1930, nenhuma delas estava politicamente envolvida na questão da deficiência (Fontes, 2011b). Em vez disso, dedicavam-se a ações de caridade, atuavam fora dos espaços públicos, nomeadamente em grupos de desporto ou espaços de encontro para pessoas cegas ou surdas. O cenário começou a mudar com a criação da Associação Portuguesa de Deficientes, em 1972, e da Associação dos Deficientes das Forças Armadas, ${ }^{2}$ em 1974. Até então a ditadura teve um impacto direto nas relações entre a sociedade civil e as estruturas do Estado. De facto, as reminiscências do tempo ditatorial estão bem refletidas no modo autoritário como o Estado se relaciona com as organizações de pessoas com deficiência. Apesar da formação de várias instituições públicas desde o restabelecimento da democracia, nomeadamente a Comissão Permanente de Reabilitação (atual Instituto Nacional para a Reabilitação) e o Conselho Nacional para a Reabilitação e Integração das Pessoas com Deficiência, as pessoas com deficiência têm permanecido apartadas dos processos de tomada de decisão que afetam as suas próprias vidas.

A fragilização da participação política das pessoas com deficiência deve tanto à parca democratização das relações entre Estado e as organizações representativas, em virtude de uma inércia sociopolítica marcada pelo autoritarismo, como à vulnerabilidade económica que pouco liberta as organizações e as pessoas com deficiência para uma ação política mais consequente. Também neste aspeto particular se faz sentir a herança da ditadura. A supressão da ideia de Estado Social - com a assunção por parte do Estado de um papel secundário na provisão de proteção social - e a afirmação de uma lógica assistencialista, na qual a deficiência se erigia mormente como

\footnotetext{
${ }^{2}$ Resultado direto da mobilização dos ex-combatentes que adquiriram deficiência na Guerra Colonial portuguesa (1961-1974).
} 
uma questão da caridade, estabeleceu uma lógica paternalista que ainda hoje se sobrepõe ao reconhecimento da autonomia política e económica enquanto direito que enriquece o espaço democrático.

Como afirma Boaventura de Sousa Santos, o Estado português, quando comparado com o dos países centrais, nunca foi um verdadeiro Estado-Providência. Este facto liga-se historicamente à sua emergência tardia (após o fim do Estado Novo, quando noutros países ele emergiu após a Segunda Guerra Mundial), exatamente quando este modelo entrava em crise nos contextos da sua criação. Assim, o que existe em Portugal é um "semi-Estado-Providência” ou um "quasi-Estado-Providência” (Santos, 1993: 20), algo que é possível avaliar no sentido técnico nas despesas investidas, mas igualmente pelo facto de

a administração pública ainda não ter interiorizado a segurança social como um direito, continuando em alguns aspetos a considerar que se trata de um favor concedido pelo Estado, tal e qual como se pensava durante o regime do Estado Novo. (Santos, 1993: 45)

Perpetuando muitas das lógicas anteriores à democracia, a exclusão social, somada ao baixo nível de apoios, relegou as pessoas com deficiência ao cuidado familiar, naturalizando a sua imagem como pessoas dependentes e incapazes de gerir as suas vidas e afastando-as das arenas da vida social onde as suas vozes poderiam ser consideradas.

Comparando com outros países europeus, o nível de proteção atingido pelo Estado-Providência português situa-se abaixo da média europeia (Gough, 1996), colocando os grupos já economicamente desfavorecidos, como é o caso das pessoas com deficiência, abaixo do limiar de pobreza (Hespanha, 2001). Um estudo recente (Portugal et al., 2010) demonstra precisamente os custos acrescidos da deficiência na sociedade portuguesa. Considerando os custos de oportunidade (educação, emprego, etc.) e os custos acrescidos para fazer face às barreiras de uma sociedade organizada de forma não inclusiva, foi possível calcular o custo de vida adicional para os agregados familiares com pessoas com deficiência, em Portugal, entre os $4103 €$ e os $25300 €$ por ano (Portugal et al., 2010).

Este quadro não deixa de ter um impacto fortíssimo na natureza das organizações e na das pessoas com deficiência. Devido às condições de vida precárias da maioria das pessoas com deficiência em Portugal, as organizações representativas centralizaram desde o início os seus esforços na melhoria das condições de vida deste grupo social. Como resultado, foi criada uma agenda orientada para a eliminação das barreiras físicas e para o acesso 
e manutenção de benefícios sociais com o objetivo de minorar os custos da exclusão. Em consequência, as organizações de pessoas com deficiência acabaram por investir a maior parte dos seus esforços no fornecimento de serviços, funcionando como uma extensão do Estado-Providência. Desta forma, os recursos humanos e materiais disponíveis nas organizações pouco se dirigem para o campo da luta política ou para um projeto mais amplo de transformação social. A realidade portuguesa reflete, assim, o reduzido empenho do Estado e a falta de capacidade da sociedade civil para transformar as condições de desigualdade social a que as pessoas com deficiência estão sujeitas; essa dupla fragilidade traduz-se, desde logo, na sistemática inconsequência das transformações legislativas.

O primeiro desafio colocado à Investigação Emancipatória da Deficiência surge, precisamente, da necessidade de apropriação de conceitos científicos e posições epistemológicas vindos de realidades diferentes. Se pensarmos que a Investigação Emancipatória da Deficiência se desenvolveu, nos anos 1970, a partir do fervilhar do ativismo político, confrontamo-nos com uma fortíssima disjunção: uma disjunção em termos da permeabilidade social a uma cultura política afirmativa dos direitos das pessoas com deficiência e em termos de uma corrente académica nascida das manifestações nas ruas circunvizinhas. Portanto, surge a questão: ao pugnarmos por uma Investigação Emancipatória da Deficiência, será que não corremos o perigo de transplantar valores e ideias sem cuidarmos da distância para com o lugar onde estes germinaram? Tal questão, defendemos, pode ser traduzida no dilema colocado por Sandra Harding (2000) quando esta reavalia as ambições universalistas e totalitárias da ciência moderna. Por um lado, a autora defende um posicionamento relativista que se opõe às pretensões universalistas da ciência moderna, afirmando que certos valores e ideias perdem a sua eficácia fora da realidade em que foram criadas. Esta crítica tem implicações políticas e epistemológicas: "O ideal universalista, em particular, é científica e politicamente disfuncional” (Harding, 2000: 124). Politicamente, esta avaliação opõe-se à arrogância ocidental perante outras formas de saber, considerados pré-modernos ou não-científicos; a este respeito as formações discursivas que foram impostas por via do colonialismo constituem uma evidência preeminente deste universalismo da modernidade ocidental. As implicações políticas são também evidentes nos jogos de poder que, "criando realidade", conferem validade a umas formações discursivas, desqualificando outras. Epistemologicamente, as críticas sublinham que certos saberes não têm aplicação, validade ou utilidade fora dos contextos em que emergiram. Segundo a autora, reconhecer este limite em determinadas ideias ou num conjunto de ideias não é afirmar a sua inerente 
fragilidade ou falsidade. O que se reconhece é o valor contextual de alguns conceitos e o facto de a sua importância no enquadramento temporal, espacial e cultural correr o risco de se perder noutros contextos.

Esta crítica mostra ter especial validade em relação a estudos que procuram compreender a realidade das pessoas com deficiência em realidades culturais cujos entendimentos da deficiência são mormente fundados em valores pouco marcados pela modernidade ocidental. Nesses contextos cabe compreender o lugar da deficiência por relação com as cosmovisões que pensam as diferenças que na modernidade ocidental aprendemos a chamar deficiências. Só uma tal perspetiva pode acalentar o ensejo de aceder ao inextrincável vínculo entre a ontologia de uma "deficiência" e as elaborações epistemológicas, sustentadas pelos diversos grupos sociais, acerca da sua causalidade e significado (Ingstad e Whyte, 1995; Martins, 2013).

Ademais, as críticas epistemológicas apontam os perigos envolvidos quando a diversidade cognitiva é desperdiçada em nome de ideais universais. "A busca de ideais universais limita a diversidade cognitiva que é e sempre foi uma fonte importante de crescimento do saber." (Harding, 2000:134). Por outro lado, Harding afirma que a crítica dos ideais universalistas, sendo importante, não deverá impedir de apreciar os pontos fortes próprios a essas ideias particulares e de avaliar a sua utilidade em contextos diferentes. Desde que uma atenção cautelar aos jogos de poder que se esgrimem seja considerada, as virtudes de uma ideia, a despeito da sua origem, deverão ser testados na sua capacidade de codificar os ideais democráticos. Estamos perante a apologia de um pragmatismo que, como defende Boaventura de Sousa Santos, anula hierarquias prévias em favor das hierarquias definidas por práticas concretas:

A ecologia de saberes assenta na ideia pragmática de que é necessária uma reavaliação das intervenções e relações concretas na sociedade e na natureza que os diferentes conhecimentos proporcionam. Centra-se, pois, nas relações entre saberes, nas hierarquias que se geram entre eles, uma vez que nenhuma prática concreta seria possível sem estas hierarquias. (Santos, 2007: 28)

Neste sentido, poderíamos dizer que a valorização da Investigação Emancipatória em Portugal constitui um teste aos méritos desta ética de pesquisa, num contexto cujo clima para um envolvimento político na investigação no campo dos estudos da deficiência está muito distante do fervor político que engendrou o seu aparecimento. Acreditamos, todavia, que existem abordagens da deficiência com maior e menor potencial emancipatório e que o modelo social da deficiência perfila a primeira opção, sobretudo ao assinalar 
as limitações do modelo médico enquanto matriz da opressão social a que as pessoas com deficiência têm sido sujeitas. Cremos, pois, que a adoção do modelo social, enquanto instrumento heurístico, poderá revelar as barreiras sociais e atitudinais responsáveis pela opressão e exclusão das pessoas com deficiência. Por outro lado, os usos do modelo social deverão ser capazes de aprofundar as reais implicações do conceito de direitos humanos, bem para além do aparente consenso criado em torno da Convenção dos Direitos das Pessoas com Deficiência. ${ }^{3}$

O segundo desafio reside na possibilidade de partilhar o planeamento e execução da pesquisa com as pessoas com deficiência. Ora, se noutros contextos esta partilha significava um engajamento com uma linguagem de direitos e com uma politização da deficiência, num território amplamente dominado pela hegemonia da perspetiva médica e reabilitacional, uma maior participação das organizações de pessoas com deficiência nem sempre significará um maior envolvimento com agendas de transformação social. Tal não significa consentir que a investigação se encerre numa "torre de marfim". A resolução deste desafio passa por um processo mútuo de aprendizagem e adaptação entre a academia e os movimentos de pessoas com deficiência, de forma a criar sinergias transformadoras das relações sociais de produção científica e da realidade social dessas pessoas.

Um terceiro desafio reside nos usos da linguagem no que à designação das "pessoas com deficiência" diz respeito. No contexto dos movimentos de pessoas com deficiência falantes de inglês, a ressignificação da deficiência fez-se também por um uso contra-hegemónico da expressão comum para a designação das "pessoas com deficiência": disabled people. Neste caso, a reconfiguração do conceito de disability para a afirmação de uma opressão vigente tornou-se particularmente eficaz na medida em que recorre a uma subtileza linguística em que a designação usada para identificar as "pessoas com deficiência”, disabled people, é apropriada como a própria afirmação da situação de opressão social. Ou seja, as disabled people, contra qualquer naturalização de uma identidade assente em características imanentes às diferenças corpóreas, são ali entendidas como as pessoas "deficientizadas" (disabled) pelos valores e formas de organização presentes na sociedade: "Disabled people are therefore an oppressed group in society" 4 (UPIAS

\footnotetext{
${ }^{3}$ A Convenção dos Direitos das Pessoas com Deficiência foi aprovada, juntamente com o Protocolo Opcional, pela Organização das Nações Unidas em dezembro de 2006 (Resolução 61/106). Em Portugal, estes documentos foram aprovados e ratificados em 2009 através das Resoluções da Assembleia da República n. ${ }^{\circ}$ 56/2009 e 57/2009 e dos Decretos do Presidente da República n. ${ }^{\circ} 71 / 2009$ e 72/2009.

${ }^{4}$ As pessoas com deficiência são, portanto, um grupo oprimido na sociedade.
} 
e Disability Alliance, 1976). Portanto, a partir das perspetivas desenvolvidas nos Princípios Fundamentais da Deficiência da UPIAS (Union of the Physically Impaired Against Segregation) e da Disability Alliance, a noção hegemónica de deficiência é disputada por uma outra, em que as implicações da deficiência não dependem dos corpos e suas diferenças (conforme modernamente definidas), mas das relações sociais que lhes dão sentido. Ora, as designações empregues em língua portuguesa, mesmo que investidas de uma desnaturalização da deficiência, invariavelmente reproduzem, ainda que mitigando, a noção hegemónica que naturaliza a deficiência enquanto atributo individual. A utilização contingente de termos como "pessoas com deficiência", "deficientes", "pessoas portadoras de deficiência”, é disso mesmo um reflexo. Se noutros contextos a politização da deficiência procura reinventar o sentido das palavras, na língua portuguesa o desafio passa, porventura, por reinventar as palavras que historicamente designam pessoas a que a modernidade nos ensinou a chamar deficientes.

Um quarto desafio tem origem na própria academia e nas instituições de financiamento de investigação em Portugal. Não obstante este não constituir um problema unicamente nacional, também aqui ele se sente de uma forma acentuada. A centralização do saber nas universidades e os tempos definidos para a construção desse saber não se coadunam, na grande maioria das vezes, com a realidade do movimento associativo das pessoas com deficiência. É, pois, necessária uma maior abertura das universidades e das instituições financiadoras a formas alternativas de saber e à participação dos sujeitos desse saber alternativo, permitindo tempos de discussão mais alargados e privilegiando uma articulação desses saberes. Só desta forma será possível alterar as relações sociais de produção científica pressupostas pelo modelo social da deficiência, permitindo uma participação igualitária de académicos e pessoas com deficiência no desenhar dos projetos de investigação, tanto na análise dos dados como na formulação de conclusões. Este desafio só poderá ser ultrapassado através da inclusão de mecanismos de participação das pessoas com deficiência em todos os projetos de investigação nesta área.

\section{Conclusão}

Pensamos que os desafios atrás enumerados obrigam a uma abordagem tentativa em que a reconfiguração da deficiência como uma questão de opressão social deve ser acompanhada por uma atenção às reflexões e histórias de vida particulares das pessoas com deficiência, bem como aos contextos em que as suas representações da experiência da deficiência tomaram forma. Por outro lado, numa lógica de horizontalidade, o processo de investigação deve ser entendido como uma coaprendizagem entre academia e pessoas 
com deficiência: as narrativas de deficiência em Portugal ensinam-nos sobre os desafios situados com que as pessoas e as organizações se confrontam; as experiências e a literatura que noutros contextos vêm reclamando uma radical politização da deficiência instigam-nos a fugir aos constrangimentos do "lugar" em que nos situamos.

Precisamos por isso de perceber os limites de uma abordagem reabilitacional e caminhar para um modelo mais social da deficiência, ou seja, importa que as respostas sociais à deficiência atentem no facto de que vivemos num regime profundamente opressivo no que às pessoas com deficiência diz respeito. Há, portanto, um caminho de transformação social mais ampla que tem que nutrir e ser nutrido por uma desestabilização das representações dominantes da deficiência e por uma vitalidade democrática. Só essa vitalidade, que carece de uma capacitação financeira das organizações de pessoas com deficiência, permitirá que a imagem pública da deficiência tenha cada vez mais que ver com uma lógica identitária onde se afirmem capacidades ante a reivindicação da superação de barreiras, em vez da linguagem compassiva ante a mão assistencialista.

É verdade que algumas ideias viajam bem, mostrando a persistência e a capacidade de se tornarem úteis em tempos e espaços diferentes do contexto da sua criação. Devemos analisar quais são as ideias que viajam bem e para onde. (Harding, 2000: 136)

De acordo com o pensamento de Harding (2000), sugerimos ao longo deste artigo que a Investigação Emancipatória da Deficiência poderá 'viajar bem' para a realidade da academia portuguesa, assim se reconheçam as especificidades que caracterizam a realidade social de destino. Nesse sentido, há que ter em conta: a ausência de uma comunidade científica sedimentada na área de estudos da deficiência; a vulnerabilidade económica e a marginalização social que inibem a participação social das pessoas com deficiência; o lastro autoritário de um Estado que afasta as organizações de pessoas com deficiência das decisões que lhes dizem respeito; as fragilidades do Estado-Providência português, que, frequentemente, levam a que as organizações de pessoas com deficiência esgotem os seus recursos na prestação de serviços.

A resolução dos quatro desafios identificados à implementação de uma investigação emancipatória na área da deficiência passa, precisamente, por esta maior autonomização das pessoas com deficiência e das suas organizações face a fenómenos de discriminação económica, social e política. Cabe perceber como se perpetuam fatores de opressão de uma significativa minoria na sociedade portuguesa que se encontra impedida de participar 
ativamente naquilo que lhe diz respeito e, logo, nos saberes que na academia têm sido produzidos sobre as suas vidas sob pretexto, muitas vezes, de uma suposta objetividade do saber científico.

Trata-se, assim, não só de construir saberes sobre a realidade das pessoas com deficiência em Portugal, mas também de produzir conhecimentos que contribuam para uma transformação social emancipatória e que exprimam o compromisso das ciências sociais na criação de uma sociedade inclusiva.

\section{Referências bibliográficas}

Abberley, Paul (1992), "Counting Us Out: A Discussion of the OPCS Disability Surveys", Disability, Handicap and Society, 7(2), 139-155.

Barnes, Colin (1991), Disabled People in Britain and Discrimination - A Case for Anti-Discrimination Legislation. London: Hurst \& Company/BCODP.

Barnes, Colin (1992), "Qualitative Research: Valuable or Irrelevant?", Disability, Handicap and Society, 7(2), 115-124.

Barnes, Colin (1997), "A Legacy of Oppression: A History of Disability in Western Culture", in Len Barton e Michael Oliver (orgs.), Disability Studies: Past, Present and Future. Leeds: The Disability Press, 3-24.

Barnes, Colin (2003), "What a Difference a Decade Makes: Reflections on Doing 'Emancipatory' Disability Research”, Disability \& Society, 18(1), 3-17.

Barnes, Colin; Mercer, Geof (2002), "The Politics of Disability and the Struggle for Change", in Len Barton (org.), Disability Politics and the Struggle for Change. London: David Fulton Publishers, 11-23.

Barnes, Colin; Mercer, Geof (2003), Disability. Cambridge: Polity Press.

Barnes, Colin; Mercer, Geof; Shakespeare, Tom (2000), Exploring Disability - A Sociological Introduction. Cambridge: Polity Press.

Barton, Len (org.) (2001), Disability, Politics \& the Struggle for Change. London: David Fulton.

Beresford, Peter (1996), "Poverty and Disabled People: Challenging Dominant Debates and Policies", Disability \& Society, 11(4), 553-567.

Campbell, Jane; Oliver, Mike (1996), Disability Politics - Understanding Our Past, Changing our Future. London: Routledge.

Coleridge, Peter (1993), Disability, Liberation and Development. Oxford: Oxfam Publishing.

Davis, Lennard J. (1995), Enforcing Normalcy: Disability, Deafness, and the Body. London: Verso.

Davis, Lennard J. (2002), Bending over Backwards: Disability, Dismodernism, and Other Difficult Positions. New York: New York University Press.

DeJong, Gerben (1981), "The Movement for Independent Living: Origins, Ideology and Implications for Disability Research”, in Ann Brechin; Penny Liddiard e John Swain 
(orgs.), Handicap in a Social World: A Reader. Sevenoaks: Hodder \& Stoughton/Open University Press, 239-248.

Drake, Robert (1999), Understanding Disability Policies. London: MacMillan.

Finkelstein, Vic (1999), “Extended Book Review - Doing Disability Research”, Disability E Society, 14(6), 859-867.

Fontes, Fernando (2009), "Pessoas com deficiência e políticas sociais em Portugal - Da caridade à cidadania social”, Revista Crítica de Ciências Sociais, 86, 73-93.

Fontes, Fernando (2011a), Social Citizenship and Collective Action: The Case of the Portuguese Disabled People's Movement. Tese de doutoramento. Leeds: University of Leeds.

Fontes, Fernando (2011b), "Deficiência e cidadania: o papel do movimento de pessoas com deficiência em Portugal”, in Regina Salvador; Ana Firmino; Cristina Ponte e Eduarda Ferreira (orgs.), Geografias de inclusão: Desafios e oportunidades. Lisboa: e-GEO, 90-101.

Gibbs, Dave (2004), "Social Model Services: An Oxymoron?”, in Colin Barnes e Geof Mercer (orgs.), Disability Policy and Practice: Applying the Social Model. Leeds: Disability Press, 144-159.

Good, Byron (1994), Medicine, Rationality and Experience: An Antbropological Experience. Cambridge: Cambridge University Press.

Gough, Ian (1996), "Social Assistance in Southern Europe”, South European Society E Politics, 1(1), 1-23.

Hahn, Hunt (1986), "Public Support for Rehabilitation: The Analysis of U.S. Disability Policy”, Disability, Handicap and Society, 1(2), 121-137.

Hahn, Hunt (2002), “Academic Debates and Political Advocacy: The US Disability Movement”, in Colin Barnes; Michael Oliver e Len Barton (orgs.), Disability Studies Today. Cambridge: Polity, 162-189.

Harding, Sandra (2000), "Should Philosophies of Science Encode Democratic Ideals", in Daniel Kleinman (org.), Science, Technology and Democracy. New York: State University of New York Press, 121-138.

Hespanha, Pedro (2001), "Mal-estar e risco social num nundo globalizado: Novos problemas e novos desafios para a teoria social", in Boaventura de Sousa Santos (org.), Globalização - Fatalidade ou utopia? Porto: Edições Afrontamento, 163-196.

Hespanha, Pedro (2008), "Políticas sociais: Novas abordagens, novos desafios", Revista de Ciências Sociais, 39(1), 5-15.

Hooks, Bell (1995), Killing Rage: Ending Racism. London: Penguin.

Hunt, Paul (1981), "Settling Accounts with the Parasite People: A Critique of 'A Life Apart' by E. J. Miller and G. V. Gwynne”, Disability Challenge, 1(5), 37-50.

Ingstad, Benedict; Whyte, Susan (orgs.), (1995), Disability and Culture. Berkeley: University of California Press.

Krieger, Linda Hamilton (2003), "Sociolegal Backlash”, in Linda Hamilton Krieger (org.) Backlash against the ADA - Reinterpreting Disability Rights. Michigan: The University of Michigan Press, 340-382. 
Longmore, Paul; Umansky, Lauri (orgs.) (2001), The New Disability History: American Perspectives. New York: New York University Press.

Martins, Bruno Sena (2006), "E se eu fosse cego?” - Narrativas silenciadas da deficiência. Porto: Edições Afrontamento.

Martins, Bruno Sena (2007), "Trilhos que tardam: As agendas perdidas da deficiência?", Cadernos Sociedade e Trabalho, VIII, 197-211.

Martins, Bruno Sena (2013) [no prelo], Sentido Sul: A cegueira no espírito do lugar. Coimbra: Almedina.

Mercer, Geof (2002), "Emancipatory Disability Research”, in Colin Barnes; Michael Oliver e Len Barton (orgs.), Disability Studies Today. Cambridge: Polity Press, 228-249.

Murphy, Robert Francis (1990), The Body Silent. New York: H. Holt.

Oliver, Michael (1990), The Politics of Disablement. London: Macmillan.

Oliver, Michael (1992), "Changing the Social Relations of Research Production?”, Disability \& Society, 7(2), 101-114.

Oliver, Michael (1996), Understanding Disability: From Theory to Practice. London: Macmillan.

Oliver, Michael (1997), “Emancipatory Research: Realistic Goal or Impossible Dream?”, in Colin Barnes e Geof Mercer (orgs.), Doing Disability Research. Leeds: The Disability Press, 15-31.

Oliver, Michael (2002), "Using Emancipatory Methodologies in Disability Research". 1st Annual disability research seminar. Consultado a 10.12.2012, em http://www. leeds.ac.uk/disability-studies/archiveuk/Oliver/Mike\%27s\%20paper.pdf.

Oliver, Michael; Barnes, Colin (1998), Disabled People and Social Policy-From Exclusion to Inclusion. Essex: Addison Wesley Longman.

Oliver, Michael; Sapey, Bob (1999), Social Work and Disabled People. London: Palgrave. OMS - Organização Mundial de Saúde (1980), International Classification of Impairments, Disabilities and Handicaps. Genève: World Health Organization.

OMS - Organização Mundial de Saúde (2001), International Classification of Functioning, Disability and Health: ICF. Genève: World Health Organisation. Versão eletrónica em português, consultada a 14.01.2013, em http://www.inr.pt/uploads/docs/cif/ CIF_port_\%202004.pdf.

Pfeiffer, David (2000), "The Devils Are in the Details: The ICIDH2 and the Disability Movement”, Disability E Society, 15(7), 1079-1082.

Portugal, Sílvia; Martins, Bruno Sena; Ramos, Luís Moura; Hespanha, Pedro (2010), Estudo de avaliação do impacto dos custos financeiros e sociais da deficiência-Relatório final. Coimbra: Centro de Estudos Sociais.

Santos, Boaventura de Sousa (1993), "O Estado, as relações salariais e o bem-estar social na semiperiferia: O caso português”, in Boaventura de Sousa Santos (org.), Portugal: Um retrato singular. Porto: Afrontamento, 17-56. 
Santos, Boaventura de Sousa (1999), "Porque é tão difícil construir uma teoria crítica?", Revista Crítica de Ciências Sociais, 54, 197-215.

Santos, Boaventura de Sousa (2002), "Para uma sociologia das ausências e uma sociologia das emergências”, Revista Crítica de Ciências Sociais, 63, 237-280.

Santos, Boaventura de Sousa (2007), "Para além do pensamento abissal: Das linhas globais a uma ecologia de saberes”, Revista Crítica de Ciências Sociais, 78, 3-46.

Stone, Emma; Priestley, Mark (1996), "Parasites, Pawns and Partners: Disability Research and the Role of Non-Disabled Researchers", British Journal of Sociology, 45(4), 699-716.

Striker, Henri-Jacques (1999), A History of Disability. Ann Arbor: University of Michigan Press.

Thomas, Carol (2002), "Disability Theory: Key Ideas, Issues and Thinkers", in Colin Barnes; Michael Oliver e Len Barton (orgs.), Disability Studies Today. Oxford: Polity Press, 38-57.

Turmusani, Majid (2002), "Work and Adulthood: Economic Survival in the Majority World”, in Mark Priestley (org.), Disability and the Life Course-Global Perspectives. Cambridge: Cambridge University Press, 192-205.

Turner, Terence (1994), "Bodies and Anti-Bodies: Flesh and Fetish in Contemporary Social Theory", in Thomas Csordas (org.), Embodiment and Experience: The Existential Ground of Culture and Self. Cambridge: Cambridge University Press, 27-46.

UPIAS - Union of the Physically Impaired against Segregation; Disability Alliance (1976), Fundamental Principles of Disability. London: UPIAS. Versão eletrónica, consultada a 12.01.2013, em http://www.leeds.ac.uk/disability-studies/archiveuk/ UPIAS/fundamental\%20principles.pdf. 
